\title{
Modeling Tourists' Departure Time considering the Influence of Multisource Traffic Information
}

\author{
Shijun Yu, ${ }^{1}$ Siyuan Zhang $\mathbb{D}^{2},{ }^{2}$ Shejun Deng $\mathbb{D}^{1},{ }^{1}$ Tao Ji, ${ }^{1}$ Peng Zhou, ${ }^{1}$ and Lang Peng ${ }^{1}$ \\ ${ }^{1}$ Yangzhou University, University South Road No. 88, Yangzhou, Jiangsu, China \\ ${ }^{2}$ Jiangsu College of Tourism, Yuxiu Road No. 88, Yangzhou, Jiangsu, China
}

Correspondence should be addressed to Siyuan Zhang; zhangsiyuan2019@126.com and Shejun Deng; dsj@yzu.edu.cn

Received 22 July 2021; Accepted 5 October 2021; Published 25 October 2021

Academic Editor: Jinjun Tang

Copyright (c) 2021 Shijun Yu et al. This is an open access article distributed under the Creative Commons Attribution License, which permits unrestricted use, distribution, and reproduction in any medium, provided the original work is properly cited.

The development of tourism brings economic benefits as well as additional pressure on the urban traffic system. For example, the travel time of tourists coincides with the rush hour of urban residents' daily commuting. Limited urban traffic resources cannot meet the travel needs of tourists and urban residents at the same time, resulting in traffic congestion and low travel efficiency. Now, with the development of intelligent technology, tourists can obtain real-time information about transportation systems through various channels and adjust their travel behavior accordingly. This study shows tourists' travel behavior based on a survey conducted to the tourists in Yangzhou city. 1500-interview data are analyzed, and a Multinomial Logit Model (MNL) was employed to establish the probability prediction model of tourists' departure time choice. The results presented that sync traffic information and some other tourism-related factors determine the choice of tourists' departure time. These factors distinguish the travel behavior of tourists from the daily travel behavior of urban residents. This study can provide suggestions for the urban tourism management department to formulate more targeted and efficient policies while creating a more comfortable tourism environment for tourists.

\section{Introduction}

With the rapid growth of economy, tourism has experienced a dramatic development. It has changed from a traditional hospitality business to a new growth point in the national social economy [1]. The development of tourism brings spiritual joy to the people and huge economic benefits to society, along with a series of accompanying effects [2-4]. The tourism traffic demand causes serious traffic congestions in many cities with tourism as a pillar industry (such as Yangzhou and Suzhou). Many traffic management policies and strategies have been taken to solve this problem, but the result is not as good as expected [5-7]. One of the most important reasons is that decision makers cannot know exactly the tourists' travel demand. Travel demand analysis studies have traditionally modeled many travel components (e.g., travel mode, departure time, and trip destination) using residents' travel data [8-11].

Many researchers have intensely focused on departure time choice, especially the workday departure time choice of urban commuters. Traditionally departure time has been modeled using discrete choice models. Bhat [12] believed that travel mode and departure time choice of urban trips are important determinants of urban travel demand and adopted a multinomial logit (MNL) model to examine the joint nature of mode and departure time choice for urban shopping trips. Lemp et al. [13] viewed departure time choice as a continuous response variable and formulated a continuous cross-nested logit (CCNL) model using Bayesian estimation techniques and San Francisco Bay Area data. Shabanpour et al. [14] adopted the discrete choice approach to model activity timing decisions and a hybrid utility maximization and developed a regret minimization model to account for the heterogeneity of decision rules across choice variables, while some recent studies have argued that because of the continuous nature of time, it is more accurate to consider it as a continuous variable. Furthermore, modeling departure time as a continuous variable frees researchers from constraints of discrete choice models. Gadda et al. [15] 
offered Bayesian estimates of continuous departure time models using accelerated failure time specifications for various trip purposes with several distributional specifications. Habib et al. [16] used a discrete-continuous econometric model to investigate the joint decisions of trip timing and mode choice for commuting trips in the Greater Toronto Area (GTA). Amirgholy et al. [17] proposed a continuum approximation model to optimize the line spacing, stop spacing, headway, and fare of the transit system. Moreover, since the mode choice decision is closely intertwined with the decision on trip departure time, several studies considered them as a joint decision to account for the interrelation or causal effects between them. Paleti et al. [18] developed an integrated model of mode and trip departure TOD choices by using both HP and stated preference (SP) data from the large-scale household travel survey undertaken in Jerusalem in 2010. Shabanpour et al. [19] presented a cluster-based joint modeling approach to investigate heterogeneous travelers' behavior toward trip mode and departure time choices by considering those choices as a joint decision.

Recently, information technologies have been rapidly advanced. They have the greatest potential for use in the research of travelers' travel behavior. In terms of data collection, different from the traditional questionnaire survey, advanced information technology makes it possible to obtain data more conveniently and accurately. Mobile communication systems such as GPS (global positioning systems), cellular phone, and RF-ID (Radio Frequency Identification) system can be used as the core instruments of tracking survey of a traveller's behavior [20]. At the same time, information technology is also widely used in the analysis of the impact on travelers' travel behavior. Hadi et al. analyzed multimodal journeys for information on transit planning using the smart card system in London by identifying the multimodal transfer combinations of bus-tounderground, underground-to-bus, and bus-to-bus. The Florida Department of Transport (FDOT) is already preparing for the expected rise of advanced traffic management strategies summarized as Intelligent Transportation Systems (ITS) [21]. Meanwhile, many studies have shown that realtime information can adapt to changing traffic conditions and assist travelers to make better travel decisions in uncertain networks [22-24].

Although all of these studies have been conducted to research urban commuters' travel behavior, the travel behavior of tourists has received relatively little attention in previous studies. Tourists share many preferences with commuters, on whom most of our knowledge of traveler behavior is based [25-27]. However, due to the restrictions of travel purpose and traffic conditions, the transportation choice behavior of tourists is significantly different from that of urban commuters. Tourists mainly travel for leisure and sightseeing, so they may choose a more comfortable mode of transportation and departure time with less urban traffic pressure. Moreover, there are fewer transportation mode options for tourists than urban commuters, and public transportation and private cars are the main ones. More importantly, tourists' travel behavior is the main factor that affects their departure time choices, such as the acquisition of real-time information around scenic spots and tour schedules. However, existing studies on departure time choice are mostly based on the characteristics of urban residents or commuters. There are only a few studies focused on modeling the travel choices of tourists during the tour based on tourist data and considering the influence of the known destination traffic information on the travel behavior of tourists.

To contribute to this gap, this study takes tourists' choice of departure time as the research object and obtains tourist data through a survey. Based on the tourist data obtained from the survey, a tourists' departure time choice prediction model is established. The model is proposed to improve the understanding of tourists' travel behavior and predict accurate tourists' travel demand. Compared with the traditional model based on urban commuters, the model proposed in this paper can more accurately describe the traffic behavior of tourists.

\section{Data Preparation}

2.1. The Influence Mechanism of Multisource Traffic Information. The multisource traffic information system provides travel information to tourists through multiple channels. The purpose is to provide multiple information to help tourists make the best travel decisions and play a role in guiding tourists' travel behavior. After obtaining multisource traffic information, tourists will recognize and judge the diversified travel information based on their understanding and then make corresponding decision-making behaviors. The basic mode of travel behavior decisionmaking of tourists under the influence of multisource traffic information is shown in Figure 1.

\subsection{Factors Affecting the Departure Time of Tourists}

2.2.1. Tourist Personal Attributes Factors. The attributes of tourists have an important influence on the choice of travel time. Due to differences in individual attributes, tourists will have different choices of travel time. Specific personal attributes include gender, age, income, and occupation.

(1) Age. The age of tourists is also one of the factors that affect the choice of departure time. Young people generally prefer a later departure time, while most elderly people generally choose an earlier departure time. At the same time, different age groups may choose different departure times due to their income level, tourism purpose, and travel distance.

(2) Income Level. Tourists with higher income pay more attention to the pursuit of comfort during the travel process, and the cost of travel has less influence on their choice of departure time. High-income groups are more inclined to individual modes of transportation and generally use private cars or taxis when traveling, so it is easier to choose a later departure time. The middle- and lower-income groups take into account the travel cost, which is an important factor considered when making travel decisions. Therefore, this 


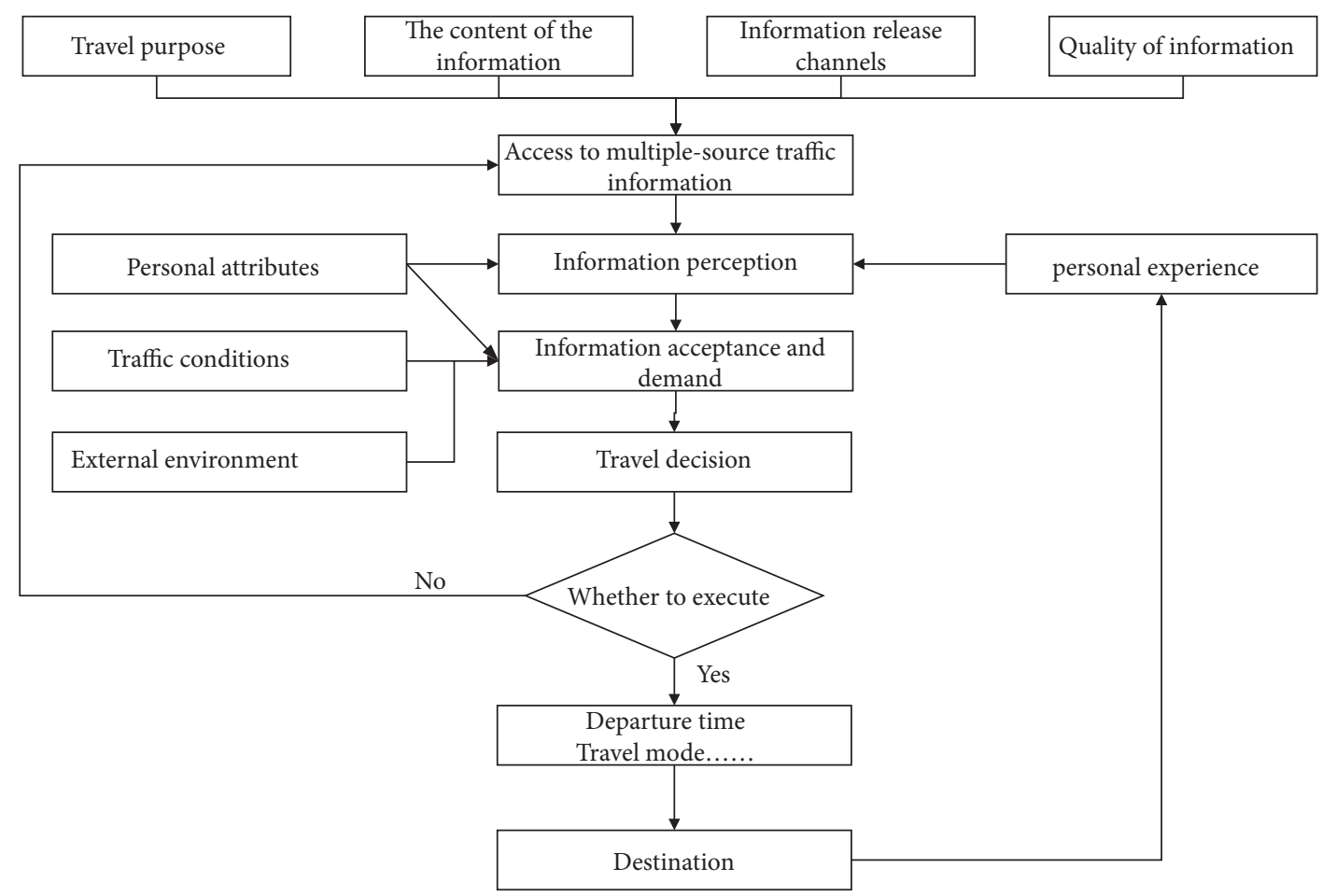

FIgURE 1: The basic function mode of the multisource traffic system.

group of tourists is highly dependent on public transportation travel modes and is more likely to choose an earlier departure time.

(3) Occupation. There is a corresponding relationship between the occupation of tourists and their income level. In general, the income level of tourists with stable occupations is relatively high. Therefore, tourists with stable careers are more likely to choose an earlier departure time.

\subsubsection{Tour-Related Factors. Tour-related factors refer to} factors that are closely related to the tourist activities, such as the frequency of trips to the city, the tour schedule, composition of people traveling together, and the desired tour experience.

(1) The Frequency of Trips to the City. This factor mainly reflects whether it is the first time for tourists to travel to the city. Generally, tourists who travel for the first time may arrange more excursions, so they will choose an earlier departure time. Conversely, tourists who have visited several times may be more likely to pursue detailed tours of some specific attractions, and it is easier to choose a later departure time.

(2) Tour Schedule. This factor directly reflects the number of days tourists will spend in this city. For example, tourists who have only one day to visit are more urgent than those who can stay for multiple days, and they may choose an earlier departure time.

(3) Composition of People Traveling Together. If the people traveling together include the elderly and children, for the elderly and children to have a better travel experience, such tourists often regard the comfort and safety of the travel process as the primary factors in travel decision-making, so they may choose early departure time. On the contrary, if there is no participation of the elderly or children, the tourists may travel more freely and may choose an earlier departure time.

2.2.3. Multisource Traffic Information-Related Factors. (1) The Ways to Obtain Travel Information. In recent years, with the rapid development of technology such as big data, information technology, and smart terminals, tourists have more and more ways to obtain traffic information, such as smartphones, navigation equipment, and broadcasting. However, tourists will rely on their habitual information acquisition ways due to differences in the effectiveness of the information update on different routes. Therefore, this will also lead to differences in the choice of departure time for tourists.

(2) The Types of Information. The information obtained by tourists is often composite rather than single, so it is necessary to know which information is in line with the actual needs of tourists and which information has a significant impact on the travel behavior of tourists. The information that tourists can obtain through the information system can be divided into three categories: traffic information, scenic area information, and external environment information. Traffic information includes real-time road conditions, public transport information, and parking information. Scenic area information mainly reflects the realtime status of the scenic area, including the number of tourists in the scenic spot, the number of queued tourists, and the ticket purchase situation. In addition, external 
information such as weather conditions is also very important for tourists' travel decisions.

2.3. Survey Design and Implementation. To minimize the possible errors in the questionnaire survey, this article considers the use of Revealed Preference (RP) investigation combined with Stated Preference (SP) investigation. In terms of survey content, the RP survey method mainly focuses on the family property, personal property, and some travel characteristics surveys of tourists, and the SP survey mainly focuses on the survey of the first choice of scenarios under hypothetical scenarios.

The questionnaire was designed to reveal three catalogs of information.

2.3.1. Basic Tourist Personal Attributes. The basic information of tourists includes gender, age, occupation, educational background, and family car ownership.

2.3.2. Tour-Related Information. It includes the tour schedule, the purpose of this tour, the composition of people traveling together, travel mode during the tour, and departure time.

2.3.3. The Use of Multisource Traffic Information. It includes the ways to obtain travel information, the types of information, and the degree of influence of travel information on tourists' travel time choices.

The survey was designed and conducted to the tourists over three days (1 to 3 May 2019), in Yangzhou city, a famous tourist city of China. We collect data on tourists visiting Slender West Lake through face-to-face interviews. They were requested to report their information by answering a questionnaire. The dataset contains detailed information of 1500 tourists' fundamental socioeconomics and demographical information, tour information, and transport information. After cleaning the dataset and removing invalid records, 1463 valid tourist questionnaires were selected for this study.

2.4. Data Collation and Analysis. By analyzing the survey data of tourists' travel time, as shown in Figure 2, it was found that the peak of tourists reaching the attractions appears between 9 am and $10 \mathrm{am}$. Considering the time spent by tourists on their way to the scenic spot, it can be inferred that the departure time of tourists may be between 8 am and 9 am. The morning peak in Yangzhou appears to be from 7 am to 9 am, and the evening peak appears to be from $5 \mathrm{pm}$ to $7 \mathrm{pm}$. The general business hours of the attractions are from 8 am to $4 \mathrm{pm}$. Taking the above conditions into consideration, we divide the departure time of tourists into three categories: before $8 \mathrm{am}$, between 8 am and 9:30 am, and between 9 am and $4 \mathrm{pm}$. These three options constitute a selection set of tourists' departure times.

The data show that the main channels for tourists to obtain traffic information are smartphones, navigation

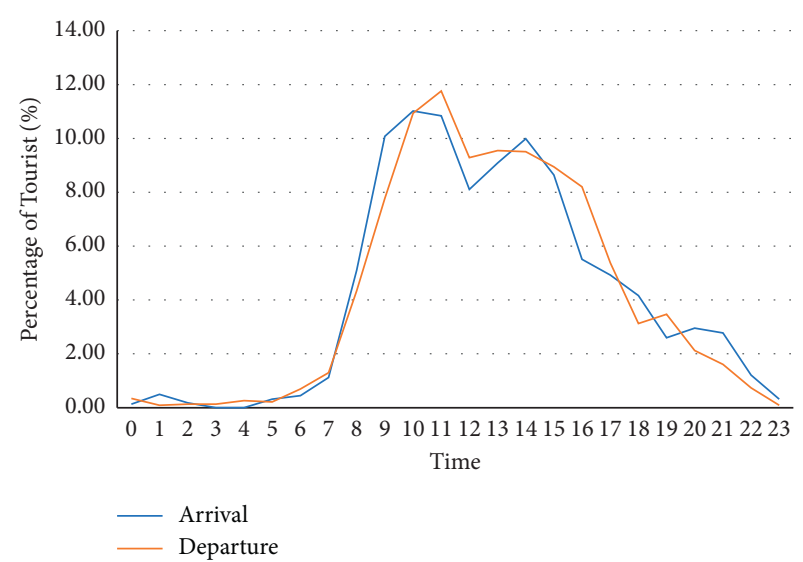

Figure 2: Tourists' travel time statistics.

equipment, and broadcasting, which account for more than $10 \%$ of the total sample. As shown in Figure 3, the use of smartphones to obtain traffic information accounted for the highest proportion of $48 \%$. Only $8 \%$ of tourists obtained travel information through roadside smart devices, indicating that tourists are relatively not reliant on it due to their unfamiliarity with the city. With the improvement of information technology, the ways for urban tourists to obtain travel information will become more and more diversified.

As shown in Figure 4, the information tourists most want to obtain includes weather information, real-time traffic information, public transportation-related information, parking information, and real-time information on the number of tourists in the target scenic spot. Public transportation information mainly includes rail or conventional bus arrival information and transfer and connection methods. Parking information mainly includes the remaining status of parking spaces and charging standards.

This article uses 1-4 to represent the degree of influence of various types of information on the departure time of tourists; 1 represents the least impact, and 4 represents the largest. As shown in Figure 5, all kinds of information will have an impact on the departure time of tourists, of which real-time traffic information and public transportation information have the greatest impact.

\section{Model Specification}

3.1. Model Selection. To predict and analyze the rules of tourists' choices of departure time, it is necessary to employ mathematical models and methods to simulate tourists' travel behavior based on collected survey data. Discrete choice models are econometric models that describe the behavior of decision makers when making choices between discrete alternatives [28]. Various types of discrete choice models have been developed and applied to a wide variety of choice situations in many diverse fields, especially in transport $[12,29,30]$.

Multiple selection problems can be divided into three categories: general multiple selection problems, ranking 


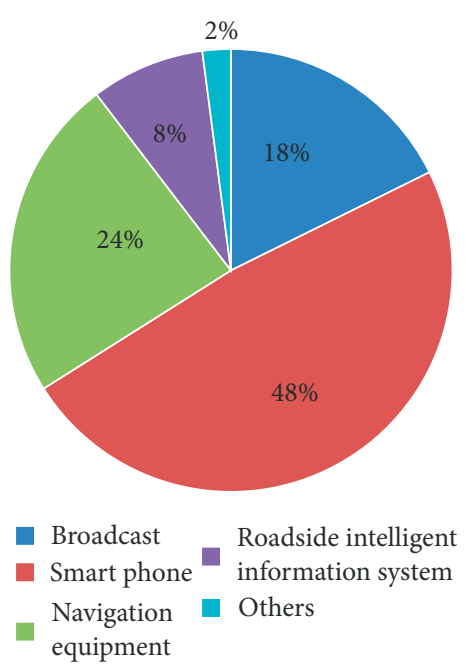

FIgURE 3: Distribution of the ways tourists obtain information.

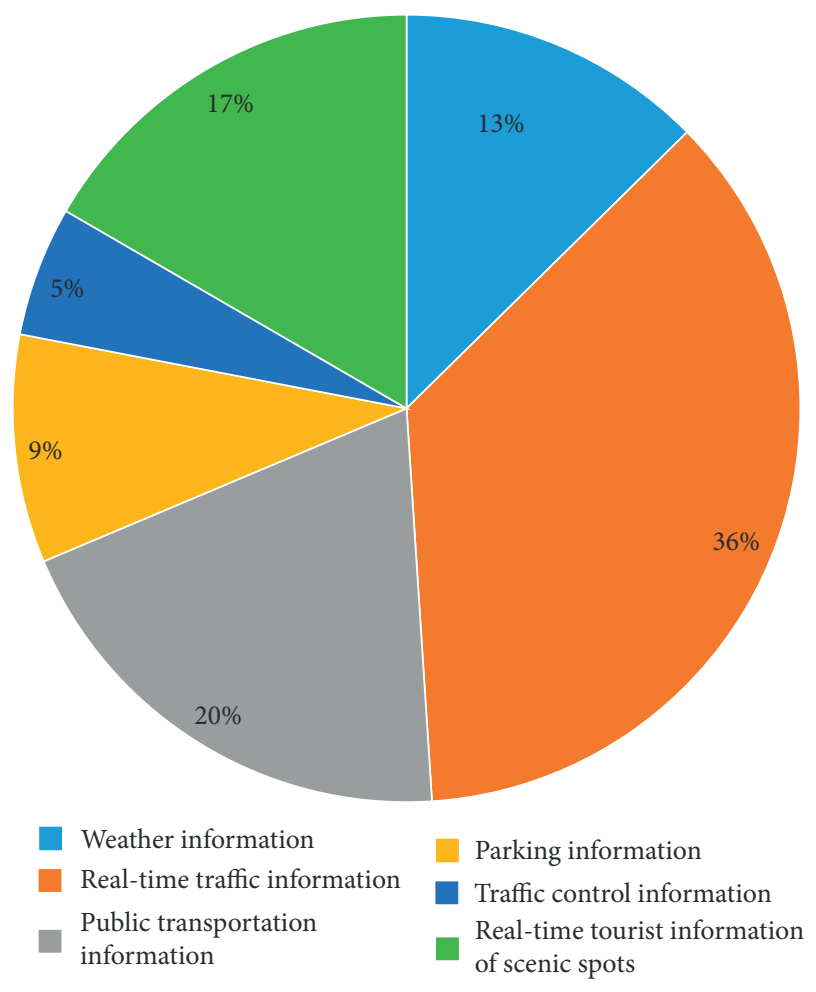

FIGURE 4: Distribution of the types of information tourists want to obtain.

selection problems, and nested selection problems. This research mainly studies tourists' departure time choice behavior during the tour, and it should be modeled by the general multiple discrete choice model. The Multinomial Logit (ML) formulation is employed in this research to describe the tourists' departure time choice behavior during the tour.

$$
P_{i n}=\frac{e^{V_{1 n}}}{\sum_{j \in A_{n}} e^{V_{j n}}} .
$$

In (1), $P_{\text {in }}$ is the probability of the tourist $n$ choosing the choice $i(i=1, \cdots, n) ; V_{\text {in }}$ is the utility function of the tourist $n$ choosing the choice $i(i=1, \cdots, n) ; A_{n}$ is the choice collection of tourists $n$.

Further, the utility function of the nth tourist choosing $i$ is

$$
V_{\text {in }}=f\left(\theta, X_{\text {in }}\right)=\sum_{k=1}^{K} \theta_{k} X_{\text {ink }} .
$$

In (2), $X_{\text {in }}$ is the influencing variable of the nth tourist choosing the ith choice; $X_{i n k}$ is the kth influencing variable of the nth tourist choosing the ith choice. $\theta_{k}$ is the corresponding parameter of the kth influence variable.

\subsection{Tourists' Departure Time Choice Model}

3.2.1. Variable Correlation Analysis. To further explore the selection behavior of tourists' departure times, this paper selects factors from three perspectives: the personal attributes of tourists, tour-related information, and the acquisition of multiple traffic information based on the data obtained from the questionnaire survey.

Firstly, it is necessary to test the correlation between independent variables and dependent variables and eliminate independent variables with small correlations. The $\mathrm{x} 2$ independence test is used to analyze the correlation between the independent variable and the dependent variable. In the results of the $\mathrm{x} 2$ independence test, for the independent variables such as age and income level, there are more than $20 \%$ of the cells having an expected frequency of less than 5, which makes the test results unreliable. Then, to ensure the reliability of the test results, the Fisher exact test in SPSS is used. The test results are shown in Table 1.

The $\mathrm{x}^{2}$ independence test and Fisher's exact test both take the $95 \%$ confidence level; that is, when the significance level $P$ value is less than 0.05 , the null hypothesis is rejected and the independent variable is considered to be correlated with the dependent variable. From the results, it can be obtained that the tourist's tour schedule, whether to drive for selfguided tours, and the real-time information acquisition are related. It can be considered that the above variables affect the choice of the tourist's departure time.

3.2.2. Tourists' Departure Time Prediction Model. (1) Variable Conversion and Screening. To use the most concise variables to build the model, it is necessary to screen the independent variables. In the disordered multicategory logistic model, four independent variable screening methods are provided, which are forward entry, backward removal, forward stepping, and backward stepping. The forward stepping method is used in this study to select independent variables.

Independent variables and dependent variables need to be transformed when they are included in the analysis model. The independent variables and dependent variables are transformed into numerical variables, and then the model parameters are calibrated, as shown in Tables 2 and 3 . 


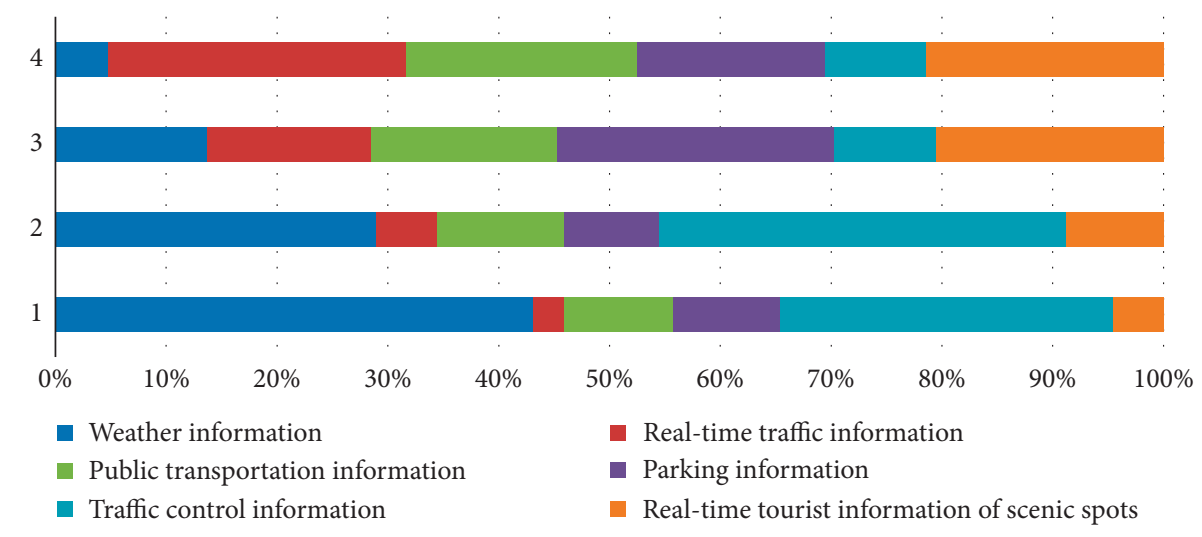

FIGURE 5: Influence degree characteristics.

TABLE 1: Correlation analysis.

\begin{tabular}{|c|c|c|c|c|}
\hline Independent variable & $\begin{array}{l}\text { Dependent } \\
\text { variable }\end{array}$ & $\begin{array}{c}P \text { value of Pearson chi-square } \\
\text { (bidirectional) }\end{array}$ & $\begin{array}{l}\text { Fisher's exact test } P \text { value } \\
\text { (bidirectional) }\end{array}$ & $\begin{array}{c}\text { Cells with an } \\
\text { expected } \\
\text { number of less than } \\
5(\%)\end{array}$ \\
\hline Gender & DT & 0.629 & 0.655 & 0.00 \\
\hline Age & DT & 0.142 & 0.183 & 38.10 \\
\hline Occupation & DT & 0.85 & 0.847 & 0.00 \\
\hline Income level & DT & 0.862 & 0.908 & 33.30 \\
\hline Family car ownership & DT & 0.917 & 0.890 & 0.00 \\
\hline Frequency of trips to Yangzhou & DT & 0.301 & 0.303 & 0.00 \\
\hline Purpose of travel & DT & 0.218 & 0.222 & 0.00 \\
\hline Tour schedule & DT & 0.013 & 0.014 & 0.00 \\
\hline Self-driving tour or group tour & DT & 0.001 & 0.001 & 0.00 \\
\hline $\begin{array}{l}\text { Composition of people } \\
\text { traveling together }\end{array}$ & DT & 0.282 & 0.270 & 16.70 \\
\hline $\begin{array}{l}\text { The number of attractions } \\
\text { planned to visit }\end{array}$ & DT & 0.242 & 0.246 & 0.00 \\
\hline $\begin{array}{l}\text { Real-time information } \\
\text { acquisition }\end{array}$ & DT & 0.007 & 0.006 & 0.00 \\
\hline
\end{tabular}

${ }^{*} \mathrm{DT}$ : departure time.

TABLE 2: Conversion value of independent variables.

\begin{tabular}{|c|c|c|}
\hline Independent variables & Category & Conversion value \\
\hline \multirow{2}{*}{ Gender $\left(x_{1}\right)$} & Male & 1 \\
\hline & Female & 2 \\
\hline \multirow{7}{*}{ Age $\left(x_{2}\right)$} & $<10$ & 1 \\
\hline & $10-19$ & 2 \\
\hline & $20-29$ & 3 \\
\hline & $30-39$ & 4 \\
\hline & $40-49$ & 5 \\
\hline & $50-59$ & 6 \\
\hline & $\geq 60$ & 7 \\
\hline \multirow{2}{*}{ Occupation $\left(x_{3}\right)$} & Have a regular occupation & 1 \\
\hline & No fixed occupation & 2 \\
\hline \multirow{4}{*}{ Income level $\left(x_{4}\right)$} & $<10$ thousand yuan & 1 \\
\hline & 10 thousand yuan -20 thousand yuan & 2 \\
\hline & 20 thousand yuan -50 thousand yuan & 3 \\
\hline & $>50$ thousand yuan & 4 \\
\hline \multirow{2}{*}{ Family car ownership $\left(x_{5}\right)$} & Yes & 1 \\
\hline & No & 2 \\
\hline
\end{tabular}


TABLE 2: Continued.

\begin{tabular}{|c|c|c|}
\hline Independent variables & Category & Conversion value \\
\hline \multirow{3}{*}{ Frequency of trips to Yangzhou $\left(x_{6}\right)$} & First time & 1 \\
\hline & Second time & 2 \\
\hline & $>$ Second time & 3 \\
\hline \multirow{2}{*}{ Purpose of travel $\left(x_{7}\right)$} & Leisure travel & 1 \\
\hline & Nonleisure travel & 2 \\
\hline \multirow{2}{*}{ Tour schedule $\left(x_{8}\right)$} & One day & 1 \\
\hline & Multidays & 2 \\
\hline \multirow{2}{*}{ Self-driving tour or group tour $\left(x_{9}\right)$} & Self-driving & 1 \\
\hline & Group tour & 2 \\
\hline \multirow{2}{*}{ Composition of people traveling together $\left(x_{10}\right)$} & Have elderly or children & 1 \\
\hline & No elderly or children & 2 \\
\hline \multirow{2}{*}{ The number of attractions planned to visit $\left(x_{11}\right)$} & $\leq 3$ & 1 \\
\hline & $>3$ & 2 \\
\hline \multirow{2}{*}{ Real-time information acquisition $\left(x_{12}\right)$} & Yes & 1 \\
\hline & No & 2 \\
\hline
\end{tabular}

(2) Model Construction and Analysis. The model is constructed based on the processed sample data, and the model fitting information is shown in Table 4.

In Table 4, the -2 times log-likelihood value is a statistic used to measure whether the logistic model fits the classified data. For the intercept-only -2 log-likelihood value and the final model -2 times, the likelihood ratio test of the difference of the log-likelihood value of 76.466 results in a $P$ value of $0.006<0.05$. The independent variables included in the model have significant explanatory power over the dependent variable, indicating that the model is meaningful. The likelihood ratio test is performed on the difference of 76.466 between the -2 times log-likelihood value of the intercept only and the -2 times log-likelihood value of the final model, and the $P$ value is $0.006<0.05$. This shows that the independent variables included in the model have significant explanatory power for the dependent variables. The model is valid and meaningful.

The parameter estimation results of the tourists departure time selection model are shown in Table 5.

According to statistical principles, under the condition of $95 \%$ confidence level, if the absolute value of the $t$-test (Wald value) is greater than 1.96, it is determined that this variable has a significant impact on the choice of travel time of tourists. The parameter estimated value and Wald value of each variable are shown in Figures 6 and 7.
According to the parameter estimation results calibrated by the above model, the tourists' departure time prediction model can be obtained as follows:

$$
\begin{aligned}
\ln \frac{P_{1}}{P_{3}}= & 1.239+0.284 X_{2}+0.606 X_{3}-0.382 X_{6}-0.737 X_{8} \\
& -1.444 X_{9}+1.029 X_{10}-0.823 X_{12}
\end{aligned}
$$

$\ln \frac{P_{2}}{P_{3}}=0.081-0.301 X_{6}-1.347 X_{9}+1.140 X_{10}-0.554 X_{12}$.

In (3) and (4), $P_{1}$ is the probability that the tourist chooses to depart before $8: 00 ; P_{2}$ is the probability that the tourist chooses to depart between 8 am and $9.30 \mathrm{am}$; $P_{3}$ is the probability that the tourist chooses to depart between $9.30 \mathrm{am}$ and $4 \mathrm{pm} ; X_{i}$ is the $i$ th independent variable.

According to the obtained tourist departure time prediction model, the probability that tourists choose to depart at each period is

$$
\begin{aligned}
\frac{P_{1}}{P_{3}} & =\operatorname{EXP}\left(1.239+0.284 X_{2}+0.606 X_{3}-0.382 X_{6}-0.737 X_{8}-1.444 X_{9}+1.029 X_{10}-0.823 X_{12}\right) \\
\frac{P_{2}}{P_{3}} & =\operatorname{EXP}\left(0.081-0.301 X_{6}-1.347 X_{9}+1.140 X_{10}-0.554 X_{12}\right) \\
P_{1}+P_{2}+P_{3} & =1
\end{aligned}
$$


TABLE 3: Conversion value of dependent variables.

\begin{tabular}{lcr}
\hline Dependent variable & Category & Conversion value \\
\hline & Before 8 am & 1 \\
Departure time & Between 8 am and $9.30 \mathrm{am}$ & 2 \\
& Between 9.30 am and $4 \mathrm{pm}$ & 3 \\
\hline
\end{tabular}

TABLE 4: Model fitting information.

\begin{tabular}{lcccc}
\hline \multirow{2}{*}{ Model } & \multicolumn{2}{c}{ Model fitting conditions } & \multicolumn{2}{c}{ Likelihood ratio test } \\
& -2 log-likelihood value & Bangla & Degree of freedom & Statistical significance \\
\hline \multirow{2}{*}{ Intercept } & 495.01 & - & - & - \\
& 418.544 & 76.466 & 48 & 0.006 \\
\hline
\end{tabular}

$$
\begin{aligned}
& P_{3}=\frac{1}{M+N+1}, \\
& P_{1}=P_{3} \cdot M \\
& P_{2}=P_{3} \cdot N \\
& M=\operatorname{EXP}\left(1.239+0.284 X_{2}+0.606 X_{3}-0.382 X_{6}-0.737 X_{8}-1.444 X_{9}+1.029 X_{10}-0.823 X_{12}\right), \\
& N=\operatorname{EXP}\left(0.081-0.301 X_{6}-1.347 X_{9}+1.140 X_{10}-0.554 X_{12}\right)
\end{aligned}
$$

$P_{1}$ is the probability that the tourist chooses to depart before $8: 00 ; P_{2}$ is the probability that the tourist chooses to depart between 8 am and $9.30 \mathrm{am} ; P_{3}$ is the probability that the tourist chooses to depart between 9.30 am and $4 \mathrm{pm} ; X_{i}$ is the $i$ th independent variable.

3.2.3. Model Verification. To verify whether the established tourists' departure time prediction model can accurately reflect the actual departure time selection behavior of tourists, this study uses survey data as the basis to compare the travel time distribution probabilities predicted by the model with the actual probability distribution of the survey. The results are shown in Table 6.

The comparative analysis of the model prediction results and the survey results shows that the model established in this study can reflect the choice behavior of tourists during the travel period, and the model has good accuracy.

3.3. Parameter Estimation Analysis. By analyzing the model obtained, it can be found that the factors that affect tourists' departure time choice are not only the personal attributes of tourists but also factors related to tourism aspects and realtime information. The combined effect of these factors together determines the departure time decision of tourists.

From Table 7, factors affecting tourists' choice of departure before or after the morning peak include age, gender, frequency of trips to Yangzhou, tour schedule, self-driving tour or group tour, the composition of people traveling together, and real-time information acquisition. The estimated values of the parameters of age and occupation in the personal attributes of tourists are positive, which indicates that young female tourists are more inclined to choose the departure time before the morning peak. Among tour-related factors, the parameter estimated values of trips to Yangzhou, tour schedule, self-driving tour, or group tour are negative, indicating that tourists who travel to Yangzhou by self-driving for the first time for a day trip are more likely to depart before the morning peak. The parameter estimated value of the factor of people traveling together is positive, indicating that tourists are more likely to choose to start before the morning peak without the company of the elderly or children. The acquisition of real-time information also has a significant impact on the choice of departure time for tourists. The estimated value of this parameter is negative, which indicates that tourists are more likely to travel after the morning peak. This may be due to the decision made by tourists to avoid the congested traffic environment based on their judgment after obtaining real-time traffic information.

In addition, some common variables appear in both formulas (3) and (4), including frequency of trips to Yangzhou, self-driving tour or group tour, composition of people traveling together, and real-time information acquisition. But except that the parameter estimates of composition of people traveling together are all positive, for the parameter estimates of other variables in the two formulas, one is positive and the other one is negative. This result shows that even the same variable has different effects on tourists' travel behavior in different time periods.

Further analysis of the data in the table, we can find that it is easier for tourists to travel to a city for the first time without the accompaniment of the elderly or children to choose an earlier departure time. At the same time, 
TABLE 5: Parameter estimation results.

\begin{tabular}{|c|c|c|c|c|c|c|c|}
\hline & Departure time ${ }^{a}$ & B & $\begin{array}{c}\text { Standard error of } \\
\text { mean }\end{array}$ & Wald & $\begin{array}{l}\text { Degree of } \\
\text { freedom }\end{array}$ & $\begin{array}{c}\text { Statistical } \\
\text { significance }\end{array}$ & $\operatorname{Exp}(B)$ \\
\hline \multirow{13}{*}{1.0} & Intercept & 1.239 & 2.252 & 0.302 & 1 & 0.582 & \\
\hline & Gender & 0.044 & 0.411 & 0.012 & 1 & 0.914 & 1.045 \\
\hline & Age & 0.284 & 0.161 & $3.090^{*}$ & 1 & 0.079 & 1.328 \\
\hline & Occupation & 0.606 & 0.456 & $1.969^{*}$ & 1 & 0.183 & 1.834 \\
\hline & Income level & -0.034 & 0.307 & 0.012 & 1 & 0.913 & 0.967 \\
\hline & Family car ownership & 0.621 & 0.472 & 1.732 & 1 & 0.188 & 1.861 \\
\hline & Frequency of trips to Yangzhou & -0.382 & 0.248 & $2.376^{*}$ & 1 & 0.123 & 0.682 \\
\hline & Purpose of travel & -0.073 & 0.494 & 0.022 & 1 & 0.883 & 0.93 \\
\hline & Tour schedule & -0.737 & 0.418 & $3.109^{*}$ & 1 & 0.078 & 0.478 \\
\hline & Self-driving tour or group tour & -1.444 & 0.611 & $5.589^{*}$ & 1 & 0.018 & 0.236 \\
\hline & $\begin{array}{l}\text { Composition of people traveling } \\
\text { together }\end{array}$ & 1.029 & 0.674 & $2.336^{*}$ & 1 & 0.126 & 2.799 \\
\hline & $\begin{array}{c}\text { The number of attractions planned to } \\
\text { visit }\end{array}$ & 0.027 & 0.421 & 0.004 & 1 & 0.948 & 1.028 \\
\hline & Real-time information acquisition & -0.823 & 0.471 & $3.049^{*}$ & 1 & 0.081 & 0.439 \\
\hline \multirow{13}{*}{2.0} & Intercept & 0.081 & 1.822 & 0.002 & 1 & 0.965 & \\
\hline & Gender & 0.2 & 0.32 & 0.39 & 1 & 0.532 & 1.221 \\
\hline & Age & 0.034 & 0.139 & 0.059 & 1 & 0.807 & 1.034 \\
\hline & Occupation & 0.243 & 0.356 & 0.465 & 1 & 0.495 & 1.274 \\
\hline & Income level & 0.039 & 0.247 & 0.024 & 1 & 0.876 & 1.039 \\
\hline & Family car ownership & 0.314 & 0.374 & 0.706 & 1 & 0.401 & 1.369 \\
\hline & Frequency of trips to Yangzhou & -0.301 & 0.195 & $2.383^{*}$ & 1 & 0.123 & 0.74 \\
\hline & Purpose of travel & -0.343 & 0.39 & 0.773 & 1 & 0.379 & 0.709 \\
\hline & Tour schedule & 0.135 & 0.341 & 0.158 & 1 & 0.691 & 1.145 \\
\hline & Self-driving tour or group tour & -1.347 & 0.453 & $8.838^{*}$ & 1 & 0.003 & 0.26 \\
\hline & $\begin{array}{c}\text { Composition of people traveling } \\
\text { together }\end{array}$ & 1.14 & 0.56 & $4.140^{*}$ & 1 & 0.042 & 3.126 \\
\hline & $\begin{array}{c}\text { The number of attractions planned to } \\
\text { visit }\end{array}$ & 0.308 & 0.333 & 0.851 & 1 & 0.356 & 1.36 \\
\hline & Real-time information acquisition & -0.554 & 0.342 & $2.625^{*}$ & 1 & 0.105 & 0.575 \\
\hline
\end{tabular}

${ }^{*} \mathrm{~B}$ is the parameter estimated value; Wald is a chi-square value; $\operatorname{Exp}(\mathrm{B})$ is the odds ratio; the reference category is 3.0 ; ${ }^{*}$ the variable is significant.

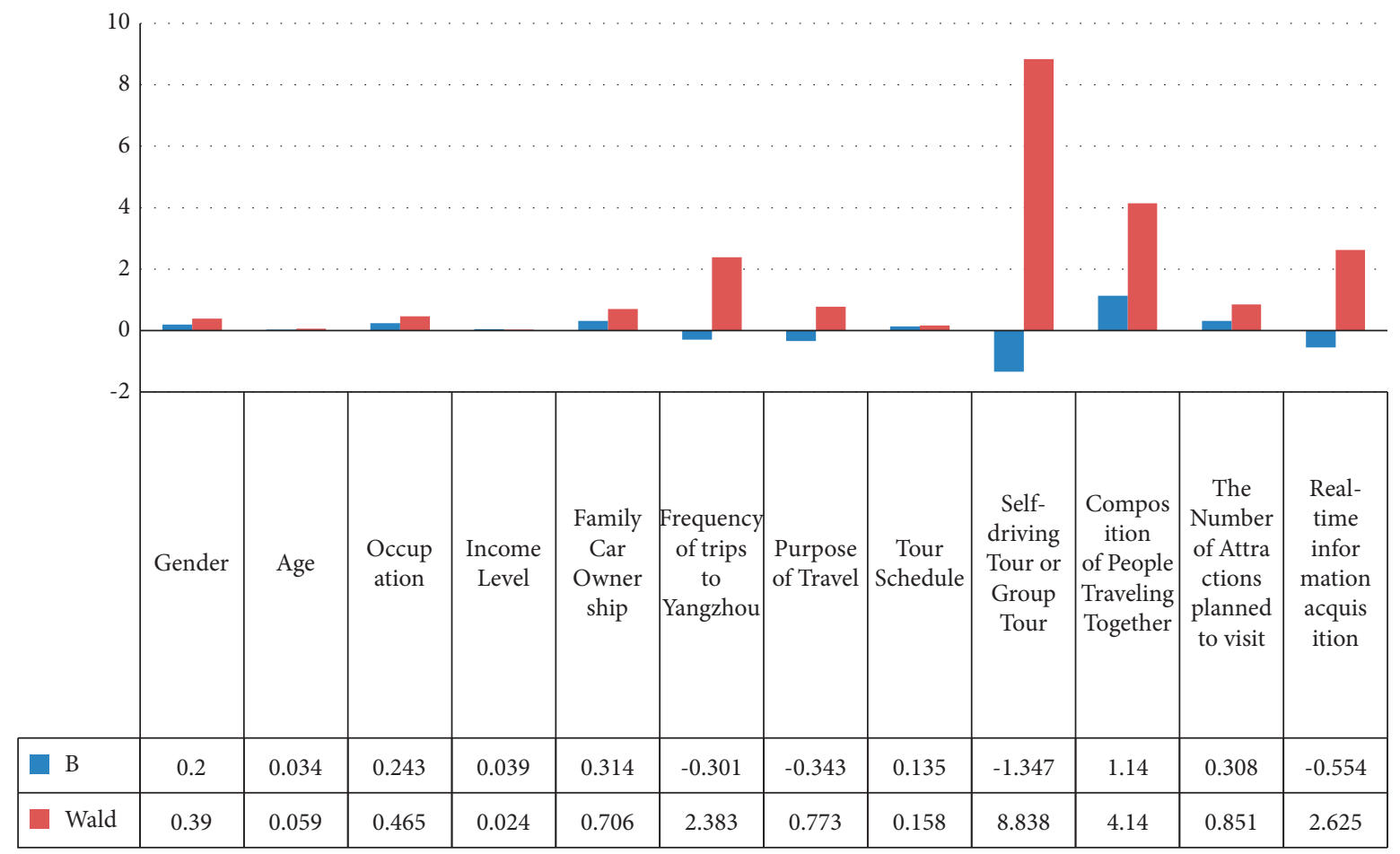

Figure 6: Value distribution of B and Wald (1). 


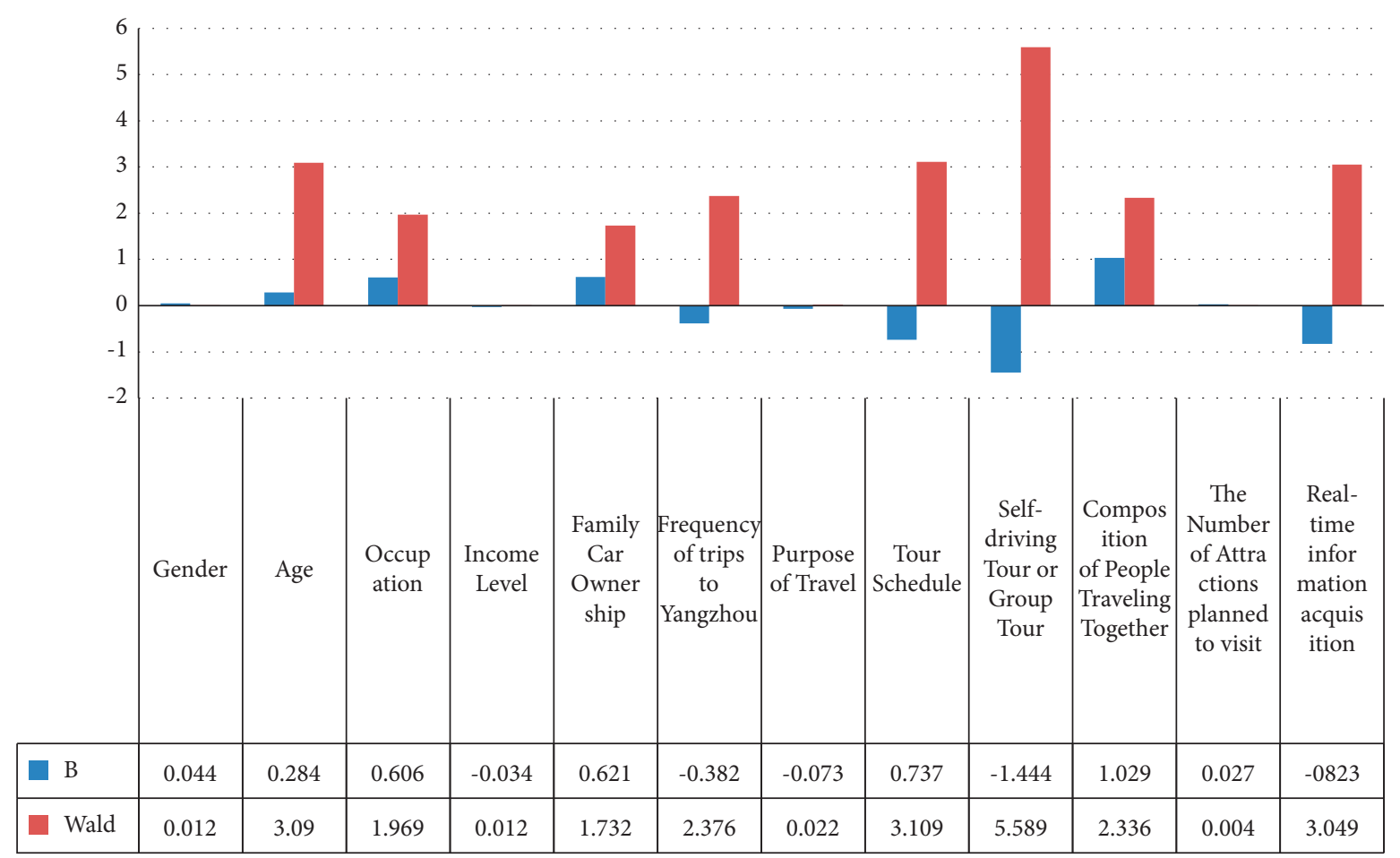

FIgURE 7: Value distribution of B and Wald (2).

TABLE 6: Model validation.

\begin{tabular}{lccc}
\hline Departure time & Model prediction probability (\%) & $\begin{array}{c}\text { Survey } \\
\text { probability } \\
(\%)\end{array}$ & Relative difference (\%) \\
\hline Before 8 am & 23.47 & 21.63 & 8.51 \\
Between 8 am and 9.30 am & 42.83 & 45.72 & -6.32 \\
Between 9.30 am and 4 pm & 33.70 & 32.65 & 3.22 \\
\hline
\end{tabular}

Table 7: Model parameter estimation results.

\begin{tabular}{|c|c|c|c|c|}
\hline \multirow{2}{*}{ Variable } & \multicolumn{2}{|c|}{1} & \multicolumn{2}{|c|}{2} \\
\hline & $\mathrm{B}$ & Wald & B & Wald \\
\hline Age & 0.284 & 3.09 & - & - \\
\hline Occupation & 0.606 & 1.969 & - & - \\
\hline Frequency of trips to Yangzhou & -0.382 & 2.376 & -0.301 & 2.383 \\
\hline Tour schedule & -0.737 & 3.109 & - & - \\
\hline Self-driving tour or group tour & -1.444 & 5.589 & -1.347 & 8.838 \\
\hline Composition of people traveling together & 1.029 & 2.336 & 1.14 & 4.14 \\
\hline Real-time information acquisition & -0.823 & 3.049 & -0.554 & 2.625 \\
\hline
\end{tabular}

${ }^{*} \mathrm{~B}$ is the parameter estimated value; Wald is a chi-square value.

according to our survey results, tourists are more inclined to choose convenient devices such as smartphones and navigation equipment to receive traffic-related information such as real-time traffic information and public traffic information. Therefore, the research results of this study have important guiding significance for the city management department to explore the travel behavior of tourists and examine how to release information that guides tourists' travel behavior through which way.

\section{Conclusion}

With the rapid development of information technology, the traffic information provided by the intelligent information platform tends to be diversified from singleness. The multisource traffic information can help tourists make reasonable travel decisions during travel, which can achieve the purpose of alleviating traffic congestion and improving the quality of travel. 
When increasing cities pay attention to taking management measures to eliminate traffic pressures caused by tourism, it is important to get deep learning about tourists' travel behavior from the angle of tourists instead of traditional urban residents and guide tourists' travel behavior through information sharing technology. The choice of departure time is an important aspect that affects the characteristics of traffic demand, as well as the factor that reflects the difference in travel behavior between tourists and urban residents.

In this study, we obtained the data of tourists traveling in Yangzhou through a survey and based on which a probability model of tourists' departure was established. Different from the previous study on departure time based on urban residents' data, the model established in this article can reveal tourists' departure time selection behavior more specifically from the perspective of tourism and information synchronization sharing. The results obtained in this research can provide a reference for obtaining more accurate tourist traffic demand and at the same time provide technical support for urban management departments to formulate more reasonable tourism traffic management measures. City management departments can guide tourists' travel behavior by publishing real-time transportation information and at the same time formulate more targeted and efficient tourism traffic management policies to alleviate the pressure of tourism traffic on urban traffic while creating a more comfortable tourism environment for tourists and promoting better tourism development.

\section{Data Availability}

The data used to support the findings of this study are included within the article.

\section{Conflicts of Interest}

The authors declare that they have no conflicts of interest.

\section{Acknowledgments}

This work was partially supported by the Research Planning Fund for Humanities and Social Sciences of the Ministry of Education (19YJAZH011), Support for the Open Project of Key Laboratory of Intelligent Traffication Technology and Traffication Industry (F262019016), and the Natural Science Foundation of Jiangsu Province BK20210833.

\section{References}

[1] Y. Y. Yu Cheng and D. X. Zhen Liu, "Review and prospect of China's tourism development," East China Economic Management, vol. 34, no. 3, pp. 1-9, 2020.

[2] D. A. Gillmor, "Evolving air-charter tourism patterns: change in outbound traffic from the Republic of Ireland," Tourism Management, vol. 17, no. 1, pp. 9-16, 1996.

[3] J. Lungren, "The development of the tourist travel systems: a metropolitan economic hegemony par excellence?" Tourist Review, vol. 23, no. 1, pp. 2-14, 1973.

[4] O. Saenz-de-Miera and J. Rosselló, "The responsibility of tourism in traffic congestion and hyper-congestion: a case study from Mallorca, Spain,” Tourism Management, vol. 33, no. 2, pp. 466-479, 2012.

[5] X. Zhao and G. Wen, "Optimizing method for evacuation route of dual-object traffic jam during peak tourist period," Journal of Yanshan University, vol. 42, no. 3, pp. 278-282, 2018.

[6] L. Wang, Y. Zhang, Q. Ji, and G. Chai, "Research on the traffic status and countermeasures in wutai mountain scenic area," Journal of Shanxi Normal University (Philosophy and Social Sciences edition), vol. 31, no. 2, pp. 121-124, 2017.

[7] M.-W. Jo, H. Kim, and H.-J. Shin, "Understanding traffic congestion to improve tourist satisfaction in local tourism," International Journal of Tourism and Hospitality Research, vol. 30, no. 4, pp. 85-95, 2016.

[8] G. Zhong, T. Yin, J. Zhang, S. He, and B. Ran, "Characteristics analysis for travel behavior of transportation hub passengers using mobile phone data," Transportation, vol. 46, no. 5, pp. 1713-1736, 2018.

[9] S. Bamberg, I. Ajzen, and P. Schmidt, "Choice of travel mode in the theory of planned behavior: the roles of past behavior, habit, and reasoned action," Basic and Applied Social Psychology, vol. 25, no. 3, pp. 175-187, 2003.

[10] M. J. Sirgy and C. Su, "Destination image, self-congruity, and travel behavior: toward an integrative model," Journal of Travel Research, vol. 38, no. 4, pp. 340-352, 2000.

[11] W. R. Zhao and Y. Zhao, "Research on passenger travel model choice in shenyang-dalian transport corridor," Applied Mechanics and Materials, vol. 744-746, pp. 2090-2093, 2015.

[12] C. R. Bhat, "Analysis of travel mode and departure time choice for urban shopping trips," Transportation Research Part B: Methodological, vol. 32, no. 6, pp. 361-371, 1998.

[13] J. D. Lemp, K. M. Kockelman, and P. Damien, "The continuous cross-nested logit model: formulation and application for departure time choice," Transportation Research Part B: Methodological, vol. 44, no. 5, pp. 646-661, 2010.

[14] R. Shabanpour, N. Golshani, J. Auld, and A. Mohammadian, "Dynamics of activity time-of-day choice," Transportation Research Record: Journal of the Transportation Research Board, vol. 2665, no. 1, pp. 51-59, 2017.

[15] S. Gadda, K. M. Kockelman, and P. Damien, "Continuous departure time models," Transportation Research Record Journal of the Transportation Research Board, vol. 2132, no. 1, pp. 13-24, 2009.

[16] K. M. N. Habib and J. A. Carrasco, "Investigating the role of social networks in start time and duration of activities: trivariate simultaneous econometric model," Transportation Research Record, vol. 2230, no. 1, pp. 1-8, 2018.

[17] M. Amirgholy, M. Shahabi, and H. O. Gao, "Optimal design of sustainable transit systems in congested urban networks: a macroscopic approach," Transportation Research Part E: Logistics and Transportation Review, vol. 103, pp. 261-285, 2017.

[18] R. Paleti, P. S. Vovsha, D. Givon, and Y. Birotker, "Joint modeling of trip mode and departure time choices using revealed and stated preference data," Transportation Research Record: Journal of the Transportation Research Board, vol. 2429, no. 1, pp. 67-78, 2014.

[19] R. Shabanpour, N. Golshani, S. Derrible, A. Mohammadian, and M. Miralinaghi, "Joint discrete-continuous model of travel mode and departure time choices," Transportation Research Record: Journal of the Transportation Research Board, vol. 2669, no. 1, pp. 41-51, 2017. 
[20] Y. Asakura and E. Hato, "Tracking survey for individual travel behaviour using mobile communication instruments," Transportation Research Part C: Emerging Technologies, vol. 12, no. 3-4, pp. 273-291, 2004.

[21] M. Hadi, X. Yan, I. Shahadat, K. Samaneh, and S. Purser II, Lehman Center of Transportation Research, Florida International University; Southwest Research Institute (SwRI). USA, Florida Department of Transportation, Tallahassee, FL, USA, 2017.

[22] G. Song and H. He, "Real-time traveler information for optimal adaptive routing in stochastic time-dependent networks," Transportation Research Part C: Emerging Technologies, vol. 21, no. 1, pp. 196-213, 2012.

[23] M. Gendreau, G. Ghiani, and E. Guerriero, "Time-dependent routing problems: a review," Computers \& Operations Research, vol. 64, pp. 189-197, 2015.

[24] J. Haworth, J. Shawe-Taylor, and T. Cheng, "Local online kernel ridge regression for forecasting of urban travel times," Transportation Research Part C: Emerging Technologies, vol. 46, pp. 151-178, 2014.

[25] L. U. Song, J. I. Hui, and C. Yunfeng, "A study on the spatial travel behavior of self-driving tourists into Huangshan City," Geographical Research, vol. 32, no. 1, pp. 179-190, 2013.

[26] H. Zhu, H. Guan, Y. Han, and W. Li, "A study of tourists' holiday rush-hour avoidance travel behavior considering psychographic segmentation," Sustainability, vol. 11, 2019.

[27] C. Mok and T. Lam, "Travel-related behavior of Japanese leisure tourists: a review and discussion," Journal of Travel \& Tourism Marketing, vol. 9, no. 1-2, pp. 171-184, 2000.

[28] M. Bierlaire, "A theoretical analysis of the cross-nested logit model," Annals of Operations Research, vol. 144, no. 1, pp. 287-300, 2006.

[29] G. D. Jong, A. Daly, M. Pieters, C. Vellay, M. Bradley, and F. Hofman, "A model for time of day and mode choice using error components logit," Transportation Research Part E: Logistics and Transportation Review, vol. 39, no. 3, pp. 245-268, 2003.

[30] D.-S. Yun, "Analysis of travel mode and home departure time choice for university students' commuting trips," Journal of Korea Planning Association, vol. 141, no. 4, 2001. 